\title{
Single umbilical artery and reproduction losses in Slovak population: relation to karyotype and fetal anomalies
}

\author{
Malova $\mathrm{J}^{1}$, Bohmer D, Luha J, Pastorakova A, Cierna Z, Braxatorisova T \\ Comenius University in Bratislava, Faculty of Medicine, Institute of Medical Biology, Genetics and Clinical \\ Genetics, Bratislava, Slovakia. jana.malova@fmed.uniba.sk
}

\begin{abstract}
AIM: The purpose of this study was to monitor the association between single umbilical artery (SUA), chromosomal abnormalities and associated anomalies during the routine examination of spontaneous or induced miscarriages and premature births.

METHODS: During 1992-2015 we morphologically and cytogenetically examined a series of 4098 samples. For 1330 cases the number of umbilical cord vessels could be reported.

RESULTS: The presence of single umbilical artery was identified in 67 fetuses of 1330 pregnancies (5.04\%); 36 of the 67 fetuses $(53.7 \%$ ) had additional congenital malformations. The cultures were unsuccessful in 29 of 67 cases (43.3\%). 38 cases (56.7\%) were successfully karyotyped; 20 out of them had a normal karyotype and 18 had chromosomal anomalies including trisomy $18(n=4)$, trisomy $13(n=3)$, trisomy $21(n=2)$, trisomy $11(n=1)$, triploidy $(n=3)$, monosomy $X(n=3)$ and structural chromosomal aberrations $(n=2)$.

CONCLUSION: Isolated SUA is not at increased risk of chromosomal abnormalities and generally does not endanger pregnancy. All chromosomally abnormal embryos and fetuses had associated congenital anomalies. The most frequently associated congenital anomalies were in the musculoskeletal system, central nervous system and genitourinary tract (Tab. 4, Ref. 44). Text in PDF www.elis.sk.

KEY WORDS: reproduction losses, single umbilical artery, congenital anomalies, karyotype, chromosomal abnormalities.
\end{abstract}

\section{Introduction}

The umbilical cord contains two arteries and one vein embedded in Wharton's jelly. The absence of one of the arteries is called single umbilical artery (SUA) and is the most common developmental abnormality of the umbilical cord.

SUA is found in $0.2-2 \%$ of deliveries (1) and occurs three or four times more frequently in twin births than in singleton births, with no difference between monochorionic (MC) and dichorionic (DC) twins (2-7). Delbaere et al (8) stated that umbilical cord anomalies are found more frequently in twins originating from assisted reproductive technologies.

Persutte and Hobbins (9) reviewed eight studies of SUA in the literature. They reported an incidence of SUA in $1.5 \%$ of spontaneous abortuses; in $7 \%$ of pregnancies that were terminated because of a severe malformation; in $0.2 \%$ to $1.6 \%$ of euploid fetuses who underwent prenatal ultrasound examination; in $9 \%$ to $11 \%$ of aneuploid fetuses, and in 0.5 to $2.5 \%$ of uncomplicated neonates.

${ }^{1}$ Comenius University in Bratislava, Faculty of Medicine, Institute of Medical Biology, Genetics and Clinical Genetics, Bratislava, Slovakia, and ${ }^{2}$ Comenius University in Bratislava, Faculty of Medicine, Institute of Pathological Anatomy, Bratislava, Slovakia

Address for correspondence: J. Malova, Institute of Medical Biology, Genetics and Clinical Genetics, Faculty of Medicine of the Comenius University Bratislava, SK-811 08 Bratislava, Slovakia.

Phone: +421.2.59357311
The single umbilical artery is reported to be associated with an increased risk of congenital anomalies, chromosomal abnormalities, fetal growth restriction, premature birth and perinatal mortality (10). While some studies have evidenced an increased incidence of fetal growth restriction and adverse outcome $(3,11)$, other investigations found no difference in the fetal growth restriction in comparison with a normal three-vessel cord $(12,13)$. Isolated SUA does not increase the risk of fetal growth restriction in uncomplicated singleton pregnancies (14). However, 30-60\% of fetuses with SUA will have associated anomalies or chromosomal abnormalities. SUA also must be considered with trisomy 13 and 18 , representing two of the most commonly reported associations $(15,16)$. SUA in the second trimester of pregnancy is highly associated with trisomy 18, 13, 21 and other chromosomal defects (17), though according to Leung (1989), trisomy 21 is not commonly associated with SUA(17). The most frequent malformations involve the skeleton, the central nervous system, the cardiovascular system, the genitourinary system and gastrointestinal tract.

This study aimed to monitor the association between SUA and chromosomal abnormalities during the routine examination of spontaneous and induced miscarriages and premature birth.

\section{Methods}

During 1992-2015 we examined a series of 4098 samples consisting of placental tissue, embryos or fetuses from spontaneous 
or induced miscarriages and premature births. Vascularisation of the umbilical cord vessels was examined in 1330 cases; in the rest (2768 samples) the umbilical cord was not present.

The samples were morphologically and cytogenetically investigated at the Institute of Medical Biology, Genetics and Clinical Genetics (Faculty of Medicine, Comenius University, Bratislava, Slovakia).

Materials were sent from 1st and 2nd Department of Gynaecology and Obstetrics, Faculty of Medicine, Comenius University

Tab. 1. Additional anomalies in spontaneous and induced miscarriages and premature births in all SUA cases $(n=67)$.

\begin{tabular}{lc}
\hline Organ system & Number of anomalies \\
\hline Central nervous system & 14 \\
Face & 12 \\
Neck & 7 \\
Heart & 11 \\
Abdominal wall & 6 \\
Gastrointestinal tract and intraabdominal organs & 2 \\
Genitourinary tract & 14 \\
Musculoskeletal anomalies & 21 \\
Total number of anomalies & 87 \\
\hline
\end{tabular}

Tab. 2. Karyotype results of fetuses with SUA in the presence and absence of other defects.

\begin{tabular}{|c|c|c|c|}
\hline \multirow{2}{*}{ Single umbilical artery } & \multicolumn{2}{|c|}{ Karyotyping } & \multirow{2}{*}{ - No karyotyping } \\
\hline & Normal & Abnormal & \\
\hline Isolated $(n=26)$ & 12 & 0 & 14 \\
\hline One defect $(n=11)$ & 1 & 3 & 7 \\
\hline Multiple defects $(n=30)$ & 7 & 15 & 8 \\
\hline Total $(n=67)$ & 20 & 18 & 29 \\
\hline
\end{tabular}

in Bratislava; 1st Clinic of Gynaecology and Obstetrics, Slovak Medical University and University Hospital in Bratislava.

The developmental age of the embryo or fetus was determined based on its size bearing in mind the differentiation of various morphological structures $(18,19,20)$.

Single umbilical artery and associated abnormalities were examined morphologically and histopathologically after delivery in all cases.

The number of umbilical vessels (two or three) was verified by histological examination. According to Romero (21), we classified developmental anomalies into 12 groups based on the affected organs. For the classical chromosomal analysis, all accessible tissues of embryonic origin (chorionic villi, umbilical cord, amniotic membrane, and embryonic or fetal tissues) were cultivated. Chromosomes were coloured conventionally and with G-banding.

\section{Results}

The presence of a single umbilical artery was identified in 67 fetuses of 1330 pregnancies (5.04\%). 36 of the 67 fetuses $(53.7$ $\%)$ had additional congenital malformations.

Additional anomalies affected the musculoskeletal system, the central nervous system, the genitourinary tract, the face, the heart, the neck, the abdominal wall, the gastrointestinal tract and intraabdominal organs (Tab. 1). The number of fetuses and embryos with SUA differs from the number of anomalies found because some fetuses have more than one anomaly.

In 29 of the 67 cases (43.3\%) karyotyping the cultivation was unsuccessful. Congenital malformations were also present in this group in 15 cases $(48.3 \%)$, including anomalies of the muscu-

Tab. 3. Aborted fetuses with single umbilical artery and normal karyotype.

\begin{tabular}{|c|c|c|c|}
\hline No. & Karyotype & Developmental age (weeks) & Anomalies \\
\hline 1 & $46, X Y$ & 5 & \\
\hline 2 & $46, \mathrm{XX}$ & 17 & Microform of cleft lip, ventricular septal defect, meromelia, adactyly of left foot \\
\hline 3 & $46, X Y$ & IInd trimester & \\
\hline 4 & $46, \mathrm{XX}$ & 17 & \\
\hline 5 & $46, X Y$ & 16 & Meckel diverticulum, horseshoe kidney \\
\hline 6 & $46, \mathrm{XX}$ & 9 & \\
\hline 7 & $46, \mathrm{XX}$ & 23 & \\
\hline 8 & $46, \mathrm{XX}$ & 24 & \\
\hline 9 & $46, \mathrm{XX}$ & 16 & Anencephaly, encephalocele, spina bifida, omphalocele \\
\hline 10 & $46, \mathrm{XX}$ & 7 & \\
\hline 11 & $46, X Y$ & 17 & \\
\hline 12 & $46, X Y$ & 25 & Bilateral renal agenesis, vitium cordis \\
\hline 13 & $46, \mathrm{XX}$ & 25 & \\
\hline 14 & $46, X Y$ & 23 & $\begin{array}{l}\text { Syndactyly of right hand }(4+5) \text {, adactyly of right hand }(1,3) \text {, right-lower extremity deformi- } \\
\text { ties, deformities of thorax }(8 \text { ribs on the right, } 11 \text { ribs on the left), aplasia of right kidney }\end{array}$ \\
\hline 15 & $46, \mathrm{XX}$ & 25 & \\
\hline 16 & $46, X Y$ & 20 & $\begin{array}{l}\text { Micrognathia, tetralogy of Fallot, spina bifida occulta, agenesis of right kidney, polycystic } \\
\text { left kidney, dilation of bladder, urethral stricture, upper-extremity phocomelia }\end{array}$ \\
\hline 17 & $46, \mathrm{XY}$ & 25 & \\
\hline 18 & $46, \mathrm{XX}$ & 23 & Meckel diverticulum, pelvic dystopia, uterus septatus \\
\hline 19 & $46, X Y$ & II $I^{\text {nd }}$ trimester & Vitium cordis \\
\hline 20 & $46, X Y$ & 33 & \\
\hline
\end{tabular}


Tab. 4. Aborted fetuses with single umbilical artery and abnormal karyotype.

\begin{tabular}{cccl}
\hline No. & Karyotype & Developmental age (weeks) & \multicolumn{1}{l}{ Anomalies } \\
\hline 1 & $47, \mathrm{XX},+13$ & 20 & Hypertelorism, micrognathia \\
\hline 2 & $47, \mathrm{XY},+13$ & 21 & Vitium cordis, postaxial polydactyly of hands, \\
\hline 3 & $47, \mathrm{XY},+13$ & 21 & Micrognathia, megaureter, hydronephrosis of kidney, talus verticalis \\
\hline 4 & $47, \mathrm{XX},+18$ & 11 & Pterygium colli \\
\hline 5 & $47, \mathrm{XY},+18$ & 17 & Micrognathia \\
\hline 6 & $47, \mathrm{XY},+18$ & 11 & Syndactyly of hands (3+4), postaxial polydactyly of hands \\
\hline 7 & $47, \mathrm{XX},+18$ & IInd trimester & Micrognathia, omphalocele \\
\hline 8 & $47, \mathrm{XY},+21$ & 23 & Renal agenesis bilat., \\
\hline 9 & $47, \mathrm{XY},+21$ & 23 & Hypertelorism, low set ears \\
\hline 10 & $47, \mathrm{XX},+11$ & 17 & Dextrocardia, ventricular septal defect, diaphragmatic hernia, renal pelvis dilation \\
\hline 11 & $69, \mathrm{XXX}$ & 13 & Hydrocephalus, cleft palate, syndactyly of hands (3+4), syndactyly of feet $(1+2+3+4+5)$ \\
\hline 12 & $69, \mathrm{XXX}$ & 13 & Hydrocephalus, syndactyly of hand (R,3+4), renal agenesis \\
\hline 13 & $69, \mathrm{XXY}$ & IInd trimester & Vitium cordis, syndactyly of hands (3+4) \\
\hline 14 & $45, \mathrm{X}$ & IInd trimester & Pterygium colli, vitium cordis \\
\hline 15 & $45, \mathrm{X}$ & 15 & Hygroma colli cysticum, swollen hands and feet \\
\hline 16 & $45, \mathrm{X}$ & 23 & Hydrocephalus, pterygium colli, clubfoot \\
\hline 17 & $45, \mathrm{X}, 10 \mathrm{p}^{+}$ & 8 & Microcephaly, pterygium colli \\
\hline 18 & $46, \mathrm{XX},-5$ pter & 17 & Microcephaly, hypertelorism \\
\hline
\end{tabular}

loskeletal system, central nervous system, face, abdominal wall, neck, heart, and genitourinary tract (Tab. 2).

38 of the 67 fetuses (56.7\%) were successfully karyotyped; 20 had a normal karyotype, and 18 had chromosomal anomalies.

Embryos and fetuses with normal karyotype were in twelve cases $(60 \%)$ without associated anomalies, in one case we found only one associated anomaly (vitium cordis) (5\%), and in seven cases $(35 \%)$ there were also other developmental anomalies detected (Tabs 2 and 3).

All fetuses with abnormal karyotype $(n=18)$ had associated developmental anomalies including trisomy $18(\mathrm{n}=4)$, trisomy $13,(n=3)$, trisomy $21(n=2)$, trisomy $11(n=1)$, triploids $(n=$ $3)$, monosomy $X(n=3)$ and structural chromosomal aberrations $(n=2)($ Tab. 4).

\section{Discussion}

Several reports have estimated the birth incidence of SUA from 0.2 to $2 \%(2-4,6-7,22-23)$.

Some authors have found that SUA is more frequent in the whites than in blacks and Asians. Considering ethnic factors, the incidence of SUA in live-born infants was $1.2 \%$ in white infants, and the incidence of SUA in live-born black infants was $0.54 \%$ $(1,23-25)$. SUA is less common in the Japanese and more common in the Eastern Europeans (21-22, 24, 26-27).

In this study of embryos and fetuses, the incidence of SUA was $5.04 \%$.

In the 1 st trimester (5-11 developmental week) the incidence of SUA was $0.98 \%(\mathrm{n}=13)$. In the second and third trimester, the incidence was $4.06 \%(\mathrm{n}=54)$.

Rembouskos (28) specifies the occurrence of SUA in the 1st trimester (11-14 week gestation) to be $5.9 \%$. In this study, the occurrence is lower, which can be caused by the small number of received samples in the 1 st trimester.

Lubusky (5) mentions in his study the occurrence in the second trimester (16-22-week gestation) to be $4.8 \%$.

The occurrence of SUA in the second and third trimester (13-33-developmental week) in our study is well comparable to his outcome.

Twins are affected three to four times more frequently than singletons. The incidence of SUA in twins reported in the literature varies between 0.8 and $11 \%(4,23)$.

In our study, SUA twins occurred only twice. In both cases the karyotyping was unsuccessful, and in both cases, SUA occurred only in one of the twins. In one case SUA was isolated, while in another case SUA was associated with clubfeet.

The association of SUA with intrauterine growth restriction (29), preterm delivery, fetal poor obstetric outcomes, and congenital anomalies has been described. Perinatal mortality is increased six times for fetuses with SUA with associated malformations, and three times for fetuses without associated malformations (2). The presence of isolated SUA would increase the risk of perinatal complications such as small for gestational age, oligohydramnios, polyhydramnios and perinatal mortality $(30,31,32,33)$. Newborns with SUA are at an increases risk for urogenital anomalies, longterm respiratory morbidity compared to newborns without SUA (34). As umbilical cord anomalies can be diagnosed prenatally, awareness and detection of the conditions in the antenatal period will improve foetal survival and reduce infant mortality (35).

Among fetuses with SUA 30-60 \% will have associated anomalies or chromosomal abnormalities (2).

Lubusky (5) detected associated sonographic abnormalities in $10.4 \%$, but Sreekumar in $47.17 \%$ (36), Hermann (37) and Leung (38) report the occurrence of abnormalities associated with SUA 
in $64 \%$ and Şener (39) in $66 \%$. In this study, associated malformations were present in 41 out of 67 cases $(61.2 \%)$, including 6 cases in the 1st trimester of pregnancy and the others in the 2nd and 3rd trimester. Associated malformation in the 2 nd trimester was present in $64.8 \%$ (35 out of 54), that is slightly higher than in other studies $(2,40)$.

An associated malformation in the 1st trimester was present in $46.2 \%$ ( 6 out of 13). The percentage is higher than that given by Martinez-Payo41 who found that $17.6 \%$ of fetuses with SUA in the 1 st trimester had a foetal malformation. Presumably, the percentage can be even higher since the young age of the fetus (5-11 developmental week) has to be considered keeping in mind the difficulties of a detailed evaluation of morphology, either because anatomical development has not been completed or due to technical limitations $(1,41)$.

The ratio of associated developmental malformations in 1 st and also in 2nd trimester is higher in our study than the values, given the fact that we treated mainly embryos from spontaneous abortions and premature births.

The most frequently associated congenital anomalies are genitourinary and cardiac (41). However, the SUA has also been associated with other anomalies including the gastrointestinal, central nervous system, and other less common ones like diaphragmatic hernias, fetal hydrops, musculoskeletal anomalies, extrophy of cloaca sequence, sirenomelia sequence, or VATER syndrome $(2,3,42)$.

Tasha (43) points out that the incidence of cardiac abnormalities among fetuses with SUA was $20.3 \%$ (37/182). However, according to Chen (44), there is no increased incidence of cardiac abnormalities among fetuses with isolated SUA.

In our investigation, according to Şenera's and Sreekumara's studies, additional anomalies most frequently affected the musculoskeletal system, the central nervous system and the genitourinary tract. Furthermore, in our series, anomalies of the face, the heart, the neck, the abdominal wall, and the gastrointestinal tract and intraabdominal organs were found.

Syndactyly and polydactyly were the most frequent anomalies of the musculoskeletal system.

In the central nervous system anencephaly, encephalocele and spina bifida, in genitourinary tract renal agenesis were present most frequently.

Micrognathia was frequent in the group of anomalies of the face, cystic hygroma and pterygium colli in the group of anomalies of the neck; and of anomalies of the abdominal wall and gastrointestinal tract, omphalocele occurred most frequently.

The cardiac abnormality was present in 11 out of 67 (16.42\%) cases of SUA, well in accord with previously published studies that reported incidences ranging from 1 to $32 \%(6,15,19)$.

These were unspecified vitium cordis (ultrasound examination), ventricular septal defect, dextrocardia and tetralogy of Fallot.

The association with chromosomal defects occurs in approximately $10 \%$ of the fetuses with SUA (41). Trisomy 18 is the most common. The next most common types of aneuploidy associated with SUA are trisomy 13 and trisomy 21.

In our sample, all embryos with an abnormal karyotype $(\mathrm{n}=$ 18) had associated developmental anomalies as well. In embryos with normal karyotype $(\mathrm{n}=20)$, we found associated developmental anomalies in $8(40 \%)$. We can conclude that all embryos/ fetuses with isolated SUA had a normal karyotype. Of embryos/ fetuses with an associated anomaly $(n=26), 18$ cases $(69 \%)$ had abnormal karyotype, and 8 cases $(31 \%)$ had a normal karyotype.

These results do not differ from the literature $(5,41)$, where chromosomal alterations were not found in fetuses with isolated SUA, and all chromosomally abnormal fetuses with SUA had associated malformations. However, in accordance with our results, some embryos with SUA and the associated anomaly had a normal karyotype as well (16).

SUA can be considered a marker of foetal malformations and chromosomal alterations. If there are any foetal malformations found, the risk of chromosomal abnormalities is increased. In cases of isolated SUA, there is no evidence of increased risk of chromosomal abnormalities.

The study is the first which deals with SUA and associated anomalies in Slovakia. Based on the fact that our set is rather big, we assume that the results are relevant and can help with the management of pregnancy. Our results are comparable to the literature from Europe, and the differences are because our set was obtained only thank to reproduction losses.

\section{References}

1. Lamberty CO, Burlacchini de Carvalho MH, Miguelez J et al. Ultrasound detection rate of single umbilical artery in the first trimester of pregnancy. Prenat Diagn 2011; 31: 865-868.

2. Gornall AS, Kurinczuk JJ, Konje JC. Antenatal detection of a single umbilical artery: does it matter? Prenatl Diagn 2003; 23: 117-123.

3. Hua M, Odibo AO, Macones GA et al. Single umbilical artery and its associated findings. Obstet Gynecol 2010; 115: 930-934.

4. Klatt J, Kuhn A, Baumann M, Raio I. Single umbilical artery in twin pregnancies. Ultrasound Obstet Gynecolol 2012; 39: 505-509.

5. Lubusky M, Dhaifalah I, Prochazka $M$ et al. Single umbilical artery and its siding in the second trimester of pregnancy: relation to chromosomal defects. Prenat Diagn 2007; 27: 327-331.

6. Martinez-Payo C, Gaitero A, Tamarit, I et al. Perinatal results following the prenatal ultrasound diagnosis of single umbilical artery. Acta Obstet Gynecol 2005; 84: 1068-1074.

7. Prucka BS, Clemens BM, Craven C, Mcpherson E. Single umbilical artery: what does it mean for the fetus? A case control analysis of pathologically ascertained cases. Genet Med 2004; 6: 54-57.

8. Delbaere I, Goetgeluk S, Derom C et al. Umbilical cord anomalies are more frequent in twins after assisted reproduction. Hum Reprod 2007; 22: $2763-2767$.

9. Persutte WH, Hobbins J. Single umbilical artery: A clinical enigma in modern prenatal diagnosis. Ultrasound Obstet Gynecol 1995; 6: 216-229.

10. Parilla BV, Tamura RK, Mac Gregor SN et al. The clinical significance of a single umbilical artery as an isolated finding on prenatal ultrasound. Obstet Gynecol 1995; 85: 570-572.

11. Burchstein S, Levy A, Holcberg $\mathbf{G}$ et al. Is single umbilical artery an indepedent risk factor for perinatal mortality? Arch Gynecol Obstet 2011; 283: 191-194. 
12. Bombrys AE, Neiger R, Hawkins $S$ et al. Pregnancy outcome in isolated single umbilical artery. Am J Perinatol 2008; 25: 239-242.

13. Wiegand S, McKenna DS, Croom C et al. Serial sonographic growth assessment in pregnancies complicated by an isolated single umbilical artery. Am J Perinatol 2008; 25: 149-152.

14. Caldas LM, Liao A,Carvalho MH et al. Should fetal growth be a matter of concern in isolated single umbilical artery? Rev Assoc Med Bras 2014; 60: 125-130.

15. Chow J, Benson C, Doubilet P. Frequency and nature of structural anomalies in fetuses with single umbilical arteries. J Ultrasound Med 1998; 17: 765-768.

16. Dagklis T, Defigueiredo D, Staboulidou I et al. Isolated single umbilical artery and fetal karyotype. Ultrasound Obstet Gynecol 2010; 36: 291-295.

17. Ferreira V, Vaz I, Reis AP et al. Antenatal detection of single umbilical artery: what does it mean? Na scer e Crescer - Revista do Hospital de Criancas Maria Pia 2013; 22, 3: 140-144.

18. Streeter GL. Developmental horizons in human embryos. Embryology Reprint, II. Washington, Carnegie Inst., 1951.

19. Moore KL. The developing human clinically oriented embryology. Philadelphia - London. Toronto, WB Sanders Comp., 2003.

20. O'Rahily R, Muller F. Devepmental Stages in Human Embryos. Washington, DC, Carnegie Inst. of Washington, 1987.

21. Romero R, Pilu G, Jeanti K et al. Prenatal diagnosis of congenital anomalies. Norwalk; Connecticut/San Mateo; California: Appleton and Lange, 1988.

22. Heifetz SA. Single umbilical artery. A statistical analysis of 237 autopsy cases and review of the literature. Perspect Pediatr Pathol 1984; 8: 345-379.

23. Wu YP, Tsai HF, Cheng YC et al. Prenatal sonographic diagnosis of single umbilical artery: Emphasis on the absent side and its relation to associated anomalies. Taiwanese J Obstet Gynecol 2014; 53: 197-201.

24. Froehlich LA, Fujikura T. Follow- up of infants with single umbilical artery. Pediatrics 1973; 52 (1): 22-29.

25. Maheshwar R, Thummala Tonse NK Raju, Langenberg P. Isolated single umbilical artery anomaly and the risk for congenital malformations: a meta-analysis. J Pediatrics Surg 1998; 33: 580-585.

26. Nishimura K, Iwatsubo T. Clinical observations of children with a single umbilical artery (Abstr). Teratology 1977; 16: 86.

27. Soma H. Single umbilical artery with congenital malformations. Curr Top Pathol 1979; 66: 159-173.

28. Rembouskos G, Cicero S, Longo D et al. Single umbilical artery at 11-14 week's gestation: relation to chromosomal defects. Ultrasound Obstet Gynecol 2003; 22: 567-570.

29. Murphy-Kaulbeck L, Dodds L, Joseph KS, van den Hof M. Single umbilical artery risk factors and pregnancy outcomes. Obstet Gynecol 2010; 116: 843-850.
30. Yajnan Xu, Lindan Ren, Shanshan Zhai et al. Association between isolated single umbilical artery and perinatal outcomes: A meta-analysis. Med Sci Monit 2016; 22.

31. Xiaohua Luo, Shanshan Yhai, Na Shi, Mei Li, Shihong Cui, Yajnan Xu, Limin Ran, Lidan Ren, Teng Hong, Rui Liu. Single Umbilical Artery in Singleton Pregnancy: A Meta-analysis. Sci Rep 2017; 7: 7396.

32. Battarbee AN, Palatnik A, Ernst LM, Grobman WA. Placental abnormalities associated with isolated single umbilical artery in small-forgestational-age births. Placenta 2017; 59: 9-12.

33. Diculescu D, Mihu D, Ciortea R, Iuhas C, Oancea M, Crihana D, Malutan A, Pop D. Ultrasound Evaluation of Pregnancies with Sigle Umbilical Artery. 5th Romanian Congress of the Romanian Society of Ultrasound in Obstetrics and Gynecology 2017; 225-230.

34. Beharier O, Sheiner E, Sergienko R, Landan D, Syaingurten-Solodkin I, Walfisch A. Isolated single umbilical artery poses neonates at increased risk of long-term respiratory morbidity. Archives of Gynecology and Obstetrics 2017; 296, 6: 1103-1107.

35. Sreekumar R, Leelabhai Janaki Y. Morphometry of umbilical cord and its relation with umbilical arteries - a foetal study. J Evol Med Dent Sci 2017; 6, 68: 4848-4852.

36. Sreekumar R, Savithri K. Prevalence of single umbilical artery and associated congenital anomalies - A foetal study. J Evol Med Dent Sci 2017; 6, 05: 402-407.

37. Hermann U, Sidiropoulos D. Single umbilical artery: Prenatal findings. Prenat Diagn 1988; 8: 275-279.

38. Leung A, Robson W. Single aumbilical artery: A report of 159 cases. Am J Dis Child 1989; 143: 108-112.

39. Şener T, Őzalp S, Hassa H et al. Ultrasonographic detection of single umbilical artery: a simple marker of fetal anomaly. Int J Gynecol Obstet 1997; 58:217-221.

40. Callen PW. Ultrasonography in obstetrics and gynecology. 4th ed. Philadelphia: Penn WB Saunders Company, 2000.

41. Martinez-Payo C, Cabezas E, Nieto Y et al. Detection of single umbilical artery in the first trimester ultrasound: Its value as a marker of fetal malformation. BioMed Res Int 2014; 6: 6 .

42. Prefumo F, Güven MA, Carvalho JS. Single umbilical artery and congenital heart disease in selected and unselected populations. Untrasound Obstet Gynecol 2010; 35: 552-555.

43. Tasha I, Brook R, Frasure H, Lazebnik N. Prenatal detection of cardiac anomalies in fetuses with single umbilical artery: Diagnostic accuracy comparison of maternal - fetal- medicine and pediatric Cardiologist. J Pregn 2014, ID265421.

44. Chen K, Akoma U, Anderson, A et al. The relationship between single umbilical artery and congenital heart disease. Am J Obstet Gynecol 2014; 210 (1): 97

Received January 26, 2018. Accepted March 1, 2018. 